\title{
Stereospecific Polymerization of Trityl, Diphenylmethyl and Benzyl Methacrylates
}

\author{
Heimei Yuki, Koichi Hatada, Toshikazu Ninomi, and Yukio KIKuchi \\ Department of Chemistry, Faculty of Engineering Science, Osaka University, Toyonaka, Osaka, Japan.
}

(Received September 8, 1969)

\begin{abstract}
Polymerizations of trityl (TMA), diphenylmethyl (DMA) and benzyl (BMA) methacrylates were carried out mainly by $n$-butyllithium ( $n$-BuLi) and the tacticities of the polymers were studied by NMR spectroscopy. Polymerization of TMA by $n$-BuLi gave a highly isotactic polymer in toluene as well as in tetrahydrofuran (THF). The polymer obtained in radical polymerization by AIBN catalyst had about $60 \%$ isotacticity in triads. From these results the growing-chain-controlled mechanism was proposed to this polymerization. In the polymerization of DMA by $n$-BuLi a highly isotactic polymer was obtained in toluene at lower temperatures and a highly syndiotactic one in THF. The radical polymerization gave a predominantly syndiotactic polymer. Temperature dependence of the NMR signal-width of the isotactic polymer indicates that the conformational arrangement of the polymer chain in solution is much rigid up to a fairly higher temperature. These results suggest that the growing-chain-controlled mechanism may contribute to some extent to the stereoregulation of DMA in toluene. BMA behaved very similarly to methyl methacrylate in the polymerization by $n$-BuLi. Probably the same polymerization mechanisms can be applied for both monomers. Polymerization of TMA, DMA and BMA by phenylmagnesium bromide or diethylaluminum diphenylamide was also investigated.
\end{abstract}

KEY WORDS Stereospecific Polymerization / Poly (Trityl Methacrylate) / Poly (Diphenylmethyl Methacrylate) / Poly (Benzyl Methacrylate) / Poly (Methyl Methacrylate) / $\boldsymbol{n}$-Butyllithium / Phenylmagnesium bromide / Diethylaluminum Diphenylamide / Growing-Chain-Controlled Mechanism of Stereoregulation / NMR Spectroscopy /

Stereospecific polymerizations of methyl ${ }^{1-3}$ and other alkyl methacrylates ${ }^{4-9}$ by anionic initiator have been extensively studied. However there have been few systematic studies ${ }^{10}$ concerning the effect of the ester group on the tacticity of polymer.

In a previous communication ${ }^{11}$ we briefly reported the polymerization of trityl methacrylate by anionic and radical initiators and found that this monomer gave a highly isotactic polymer regardless of the polymerization medium, the temperature and the type of initiator. In the present work the polymerizations of trityl (TMA), diphenylmethyl (DMA) and benzyl (BMA) methacrylates were carried out mainly by $n$-butyllithium ( $n$-BuLi) and the effect of the bulkiness of the ester group on the tacticity of the polymer was investigated.

\section{EXPERIMENTAL}

\section{Materials}

TMA was prepared from silver methacrylate and trityl chloride in diethyl ether. ${ }^{12}$ The crude product was purified by recrystallization from petroleum ether. $\mathrm{mp} 102-103^{\circ} \mathrm{C}$ (lit. ${ }^{12} 101-$ $103^{\circ} \mathrm{C}$ ), Anal. Found: C, 84.00; H, $6.08 \%$. Calcd for $\mathrm{C}_{23} \mathrm{H}_{20} \mathrm{O}_{2}$ : C, 84.12; H, 6.14\%. The NMR spectrum $\left(10 \% \quad \mathrm{CCl}_{4}\right.$ solution) showed peaks at $1.90 \mathrm{ppm}$ (singlet, $2.95 \mathrm{H}$ ) assigned to the methyl protons, 5.49 and $6.13 \mathrm{ppm}$ (two singlets $2.00 \mathrm{H})$ assigned to the $\beta$-protons of the vinyl group and about $7.20 \mathrm{ppm}$ (multiplet, 15.2H) assigned to the phenyl protons.

DMA was prepared by the reaction of $45 \mathrm{~g}$ of silver methacrylate and $39 \mathrm{~g}$ of diphenylmethyl chloride in $300 \mathrm{~m} l$ of diethyl ether under reflux 
for $8 \mathrm{hr}$. The etheral layer was separated from the reaction mixture by filtration and the residual solid was washed three times with ether. All the etheral solutions were combined and the ether was removed, leaving $20 \mathrm{~g}$ crystalline solid which was recrystallized from petroleum ether. Sixteen grams of purified product were obtained. mp 78-79 ${ }^{\circ} \mathrm{C}$, Anal. Found: C, 80.88; H, 6.27\%. Calcd for $\mathrm{C}_{17} \mathrm{H}_{16} \mathrm{O}_{2}$ : C, 80.92; $\mathrm{H}, 6.39 \%$. The NMR spectrum $\left(10 \% \mathrm{CCl}_{4}\right.$ solution) showed peaks at $1.96 \mathrm{ppm}$ (singlet, $3.00 \mathrm{H}$ ) assigned to the $\alpha$-methyl protons, 5.51 and $6.17 \mathrm{ppm}$ (two singlets $2.00 \mathrm{H}$ ) assigned to the $\beta$-protons of the vinyl group, $6.86 \mathrm{ppm}$ (singlet, 1.10H) assigned to the methine proton of the ester group and $7.24 \mathrm{ppm}$ (singlet with fine splittings $10.3 \mathrm{H}$ ) assigned to the phenyl protons.

Diphenylmethyl chloride was prepared from diphenylcarbinol and hydrogen chloride. The carbinol was prepared by the reaction of phenylmagnesium bromide and benzaldehyde according to the procedure of Marshall. ${ }^{13}$

BMA was prepared from methyl methacrylate and benzyl alcohol by an ester interchange technique $^{14}$ using $\mathrm{H}_{2} \mathrm{SO}_{4}$ catalyst. The crude product was fractionally distilled under reduced pressure. bp $86.0^{\circ} \mathrm{C}(1 \mathrm{mmHg})$. The NMR spectrum $\left(10 \% \mathrm{CCl}_{4}\right.$ solution) showed peaks at $1.93 \mathrm{ppm}$ (singlet, $3.05 \mathrm{H}$ ) assigned to the methyl protons, $5.11 \mathrm{ppm}$ (singlet, 2.02H) assigned to the benzyl methylene protons, 5.49 and $6.08 \mathrm{ppm}$ (two singlets, $2.00 \mathrm{H}$ ) assigned to the $\beta$-protons of the vinyl group and $7.27 \mathrm{ppm}$ (singlet with fine splittings, $5.10 \mathrm{H}$ ) assigned to the phenyl protons.

Toluene was purified and dried by the usual method $^{15}$ and was distilled over calcium hydride. Then it was mixed with a small amount of $n$-BuLi (toluene solution) and redistilled under high vacuum just before use.

Tetrahydrofuran (THF) was refluxed and distilled over calcium hydride, and was redistilled over lithium aluminum hydride under high vacuum just before use.

$n$-Hexane was purified in the usual manner ${ }^{15}$, and was dried and stored over calcium hydride. This was mixed with a small amount of $n$-butyllithium dissolved in $n$-hexane and distilled under high vacuum just before use.

Nitrobenzene, benzene, carbon tetrachloride and chloroform were purified and dried in the usual manner. ${ }^{15}$

$n$-BuLi was prepared in $n$-hexane according to Ziegler's method ${ }^{16}$ from $n$-butyl chloride and metallic lithium under argon atmosphere and was used as a $0.5 \mathrm{~mol} / l$ solution.

Phenylmagnesium bromide $(\mathrm{PhMgBr})$ was prepared from phenyl bromide and magnesium in diethyl ether and the solvent ether was replaced with toluene by distillation.

Diethylaluminum diphenylamide $\left(\mathrm{Et}_{2} \mathrm{AlNPh}_{2}\right)$ was prepared by the reaction of triethyl aluminum and diphenylamine in toluene at $60^{\circ} \mathrm{C}^{17}$ and used as a toluene solution of $0.5 \mathrm{~mol} / l$.

Nitrogen and argon were purified by being passed through a column packed with molecular sieves $4 \mathrm{~A}$ cooled at $-78^{\circ} \mathrm{C}$ in a dry ice-acetone bath.

\section{Polymerization}

In a glass ampoule equipped with a three-way stopcock was placed the solid monomer and the ampoule was flushed with dry nitrogen. Then the solvent was introduced into the ampoule with a hypodermic syringe. In the polymerization of benzyl methacrylate the monomer was introduced with a hypodermic syringe after flushing with nitrogen. To the monomer solution cooled at a given temperature the catalyst solution was added by a hypodermic syringe and the ampoule was immediately sealed off.

After the desired reaction time the polymerization was stopped by adding a small amount of methanol and the polymer was precipitated by pouring the mixture into a large amount of methanol. After standing overnight, the polymer was collected by filtration, washed with methanol and dried in vacuo at an elevated temperature.

Conversion of Poly (Trityl Methacrylate) (PTMA) to Poly (Methyl Methacrylate) (PMMA)

PTMA was quantitatively hydrolyzed to poly(methacrylic acid) by refluxing in methanol containing $0.5 \%$ hydrochloric acid for $3 \mathrm{hr}$. The poly (methacrylic acid) obtained was methylated with diazomethane in THF by the procedure of Katchalsky and Eisenberg ${ }^{18}$. The tacticity of the original PTMA was estimated by the measurements of the NMR spectrum of this derived PMMA. 


\section{Measurements}

NMR spectra were obtained with a JNM-4H100 spectrometer (JEOL) at $100 \mathrm{MHz}$ using tetramethylsilane as an internal reference. The spectrum of PMMA was measured in chloroform at $60^{\circ} \mathrm{C}$ and the tacticity was determined as described by Bovey and Tiers ${ }^{19}$. The spectra of poly (diphenylmethyl methacrylate) (PDMA) and poly (benzyl methacrylate) (PBMA) were taken on a $10 \%$ nitrobenzene- $d_{5}$ solution at $160^{\circ} \mathrm{C}$. The tacticity of PBMA was determined from the $\alpha$-methyl proton signals according to Ishii. ${ }^{20}$

The solution viscosity of the polymer was determined in benzene at $30.0 \pm 0.02^{\circ} \mathrm{C}$ using a Ubbelohde type viscometer.

\section{RESULTS}

\section{Polymerization of Trityl Methacrylate}

The polymerization of trityl methacrylate by $n$-BuLi was carried out at various temperatures. The results were shown in Table I. When the polymerization was carried out in toluene at $-78^{\circ} \mathrm{C}$, a highly isotactic polymer with a melting point of about $250^{\circ} \mathrm{C}$ was obtained. The tacticity of the polymer was little dependent on the polymerization temperature and the polymers

Table I. Polymerization of TMA by $n-\mathrm{BuLi}^{\mathrm{a}}$

\begin{tabular}{|c|c|c|c|c|c|c|c|}
\hline \multirow{2}{*}{ No. } & \multicolumn{2}{|c|}{ Solvent $(\mathrm{m} l)$} & \multicolumn{2}{|c|}{ Polymerization } & \multicolumn{3}{|c|}{ Tacticity $(\%)$} \\
\hline & Toluene & THF & $\begin{array}{c}\text { Temp. } \\
\left({ }^{\circ} \mathrm{C}\right)\end{array}$ & $\begin{array}{l}\text { Yield } \\
(\%)\end{array}$ & I & $\mathrm{H}$ & $S$ \\
\hline 15 & 10 & $\mathbf{0}$ & -78 & 21 & 96 & 2 & 2 \\
\hline 16 & 10 & 0 & -40 & 81 & 98 & 2 & 0 \\
\hline 17 & 10 & 0 & 0 & 58 & 93 & 4 & 3 \\
\hline 1 & 10 & 0 & 60 & 0 & - & - & - \\
\hline $10^{\mathrm{b}}$ & 5 & 5 & -78 & 67 & 96 & 3 & 1 \\
\hline 21 & 0 & 10 & -78 & 13 & 94 & 4 & 2 \\
\hline
\end{tabular}

a Monomer $5 \mathrm{mmol}$; $n$-BuLi $0.25 \mathrm{mmol}$; Time $24 \mathrm{hr}$

b Time $144 \mathrm{hr}$ obtained at -40 and $0^{\circ} \mathrm{C}$ were also highly isotactic. They were all insoluble in the usual organic solvents. A maximum yield of the polymer was obtained at $-40^{\circ} \mathrm{C}$ and no polymerization occurred at $60^{\circ} \mathrm{C}$ and above.

When the polymerization was carried out in toluene-THF or THF at $-78^{\circ} \mathrm{C}$, a highly isotactic polymer was also obtained.

The radical polymerization by AIBN gave a polymer in good yield (Table II). The polymer had about $60 \%$ isotacticity in triads. The value 4IS/ $/ \mathrm{H}^{2}$ can be taken as the indication of the mechanisms of stereoregulation. It was much larger than unity for this radical polymerization, suggesting that the stereoregulation in this polymerization can not be described by a single parameter process. ${ }^{19}$

No polymerization occurred by $\mathrm{Et}_{2} \mathrm{AlNPh}_{2}$ or $\mathrm{PhMgBr}$.

\section{Polymerization of DMA}

Figure 1 shows the NMR spectra of two samples of PDMA, one obtained in toluene and the other in THF by $n$-BuLi at $-78^{\circ} \mathrm{C}$. Both spectra consist of four signal groups corresponding to phenyl, methine, $\beta$-methylene and $\alpha$-methyl protons, respectively. The $\beta$-methylene resonance of the polymer obtained in toluene is an $\mathrm{AB}$ quartet centered at $2.08 \mathrm{ppm}$. On the other hand the resonance of the polymer prepared in THF appears as a singlet, although somewhat broadened. These results clearly show that the polymer prepared in toluene has a predominantly isotactic configuration and the polymer obtained in THF is predominantly syndiotactic. Thus the $\alpha$ methyl signal at $1.09 \mathrm{ppm}$ can be assigned to $\alpha$ methyl groups of the central monomer units in isotactic triads and that at $0.68 \mathrm{ppm}$ to the $\alpha$ methyl groups in syndiotactic configurations. The $\alpha$-methyl band at $0.82 \mathrm{ppm}$ in the bottom

Table II. Polymerization of TMA by various catalysts in toluene

\begin{tabular}{|c|c|c|c|c|c|c|c|c|c|}
\hline \multirow{2}{*}{ No. } & \multirow{2}{*}{ Catalyst } & \multirow{2}{*}{$(\mathrm{mmol})$} & \multicolumn{2}{|c|}{ Polymerization } & \multirow{2}{*}{ Yield $(\%)$} & \multicolumn{3}{|c|}{ Tacticity $(\%)$} & \multirow{2}{*}{$4 \mathrm{IS} / \mathrm{H}^{2}$} \\
\hline & & & Temp. $\left({ }^{\circ} \mathrm{C}\right)$ & Time (hr) & & I & $\mathrm{H}$ & $\mathrm{S}$ & \\
\hline 14 & AIBN & 0.05 & 30 & 144 & 82 & 63 & 23 & 14 & 6.46 \\
\hline 6 & AIBN & 0.05 & 60 & 144 & 92 & 64 & 22 & 14 & 6.79 \\
\hline 37 & $\mathrm{Et}_{2} \mathrm{AlNPh}_{2}$ & 0.5 & -40 & 92 & 0 & - & - & - & - \\
\hline 65 & $\mathrm{PhMgBr}$ & 0.28 & 30 & 24 & 0 & - & - & - & - \\
\hline
\end{tabular}

${ }^{a}$ Monomer $5 \mathrm{mmol}$, Toluene $10 \mathrm{~m} l$. 


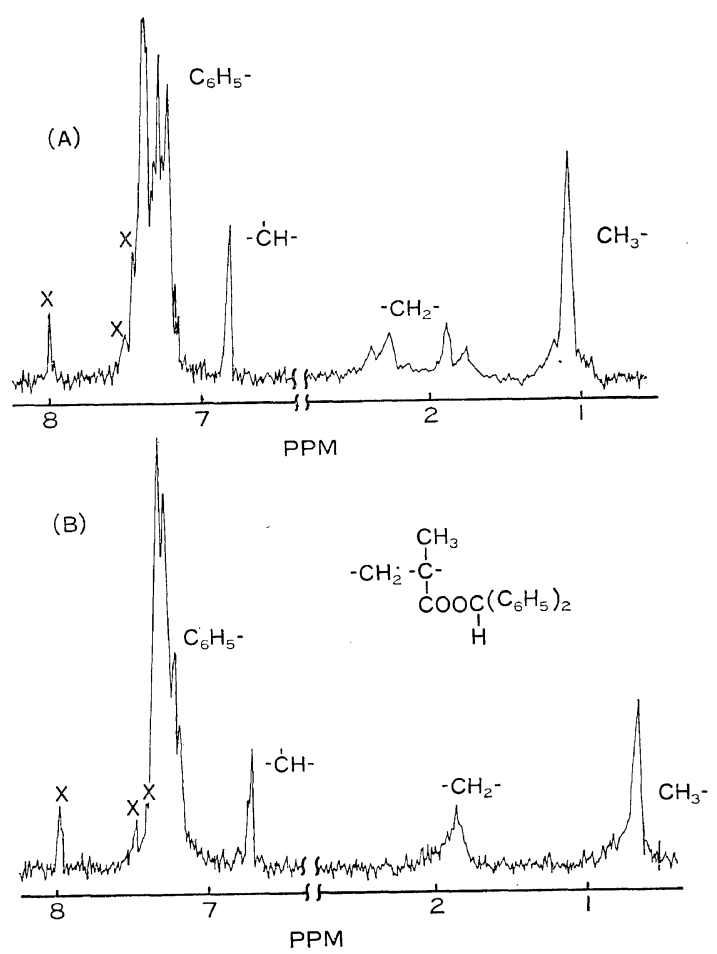

Figure 1. NMR spectra of (A) isotactic and (B) syndiotactic PDMAs in nitrobenzene- $d_{5}$.

(A) Prepared in toluene by $n$-BuLi at $-78^{\circ} \mathrm{C}$

(B) Prepared in THF by $n$-BuLi at $-78^{\circ} \mathrm{C}$ The peaks labelled $\mathrm{X}$ are due to the phenyl protons of nitrobenzene.

spectra is assigned to heterotactic triads.

The methine protons of the ester group in isotactic and syndiotactic configurations have different chemical shifts at 6.82 and 6.71 , respectively. The multiplet of phenyl protons in the spectrum of isotactic polymers is different in its fine splittings from that of syndiotactic polymers.

Although all the signals appeared to be sensitive to the stereochemical configuration of the polymer, the fraction of tactic triads was determined by the intensity measurements of the three $\alpha$-methyl signals. The chemical shift differences among these three peaks are sufficiently large and the intensity measurement can be done accurately.

Polymerization of DMA was carried out in toluene by $n$-BuLi. The results are shown in Table III. The yield of the polymer was increased by increasing the polymerization temperature.
Table III. Polymerization of DMA in toluene by $n$-BuLi ${ }^{a}$

\begin{tabular}{|c|c|c|c|c|c|c|}
\hline \multirow{2}{*}{ No. } & \multirow{2}{*}{$\underset{\left({ }^{\circ} \mathrm{C}\right)}{\text { Temp. }}$} & \multirow{2}{*}{$\begin{array}{c}\text { Yield } \\
(\%)\end{array}$} & \multicolumn{3}{|c|}{ Tacticity $(\%)$} & \multirow{2}{*}[\eta]{$(\mathrm{d} l / \mathrm{g})$} \\
\hline & & & I & $\mathrm{H}$ & $S$ & \\
\hline 32 & -95 & 24 & 99 & 1 & 0 & 0.09 \\
\hline 17 & -78 & 86 & 99 & 1 & 0 & 0.19 \\
\hline 18 & -20 & 90 & 99 & 1 & 0 & 0.22 \\
\hline 29 & 0 & 84 & 93 & 4 & 3 & 0.20 \\
\hline 30 & 30 & 83 & 92 & 5 & 3 & - \\
\hline 31 & 60 & 24 & 80 & 12 & 8 & 0.08 \\
\hline
\end{tabular}

a Monomer $5 \mathrm{mmol}$, Toluene $10 \mathrm{ml}, n$-BuLi 0.25 mmol, Time $24 \mathrm{hr}$.

It passed through a maximum at $-20^{\circ} \mathrm{C}$ and then fell off. The polymer obtained was soluble in benzene, toluene, nitrobenzene and chloroform. The maximum solution viscosity was also obtained with polymer prepared at the polymerization temperature of $-20^{\circ} \mathrm{C}$. The polymer obtained at lower temperature had a highly isotactic configuration, although the isotacticity was slightly decreased by increasing the polymerization temperature.

When the polymerization was carried out in THF by $n$-BuLi at $-95^{\circ} \mathrm{C}$, the polymer having a mainly syndiotactic configuration was obtained. By increasing the polymerization temperature the fraction of syndiotactic triads decreased in association with an increase in the fraction of heterotactic triads (Table IV).

Table IV. Polymerization of DMA in THF by $n-\mathrm{BuLi}^{\mathrm{a}}$

\begin{tabular}{|c|c|c|c|c|c|c|c|}
\hline \multirow{2}{*}{ No. } & \multirow{2}{*}{$\underset{\left({ }^{\circ} \mathrm{C}\right)}{\text { Temp. }}$} & \multirow{2}{*}{$\begin{array}{c}\text { Yield } \\
(\%)\end{array}$} & \multicolumn{3}{|c|}{ Tacticity $(\%)$} & \multirow{2}{*}[\eta]{$(\mathrm{d} l / \mathrm{g})$} & \multirow{2}{*}{$4 \mathrm{IS} / \mathrm{H}^{2}$} \\
\hline & & & I & $\mathrm{H}$ & $\mathrm{S}$ & & \\
\hline 33 & -95 & 85 & 2 & 12 & 86 & - & 4.77 \\
\hline 21 & -78 & 93 & 2 & 11 & 87 & 0.16 & 5.74 \\
\hline 22 & -30 & 93 & 4 & 12 & 84 & - & 9.35 \\
\hline 34 & 0 & 89 & 2 & 31 & 67 & 0.10 & 0.56 \\
\hline 35 & 30 & 57 & 4 & 36 & 60 & - & 0.74 \\
\hline 36 & 60 & 51 & 5 & 44 & 51 & 0.05 & 0.53 \\
\hline
\end{tabular}

a Monomer $5 \mathrm{mmol}$, THF $10 \mathrm{~m} l, n$-BuLi $0.25 \mathrm{mmol}$, Time $24 \mathrm{hr}$.

The results of the polymerization by other initiators are shown in Table V. The polymerization in toluene by the $\mathrm{AIBN}$ or $\mathrm{Et}_{2} \mathrm{AlNPh}_{2}$ catalyst gave an atactic polymer having about $60 \%$ syndiotactic triads in good yield. When the polymerization was initiated by $\mathrm{PhMgBr}$ in toluene, 
Table V. Polymerization of DMA in toluene by various catalysts ${ }^{\mathrm{a}}$

\begin{tabular}{|c|c|c|c|c|c|c|}
\hline \multirow{2}{*}{ No. } & \multirow{2}{*}{ Catalyst } & \multirow{2}{*}{ (mmol) } & \multirow{2}{*}{$\begin{array}{c}\text { Temp. } \\
\left({ }^{\circ} \mathrm{C}\right)\end{array}$} & \multirow{2}{*}{$\begin{array}{c}\text { Yield } \\
(\%)\end{array}$} & \multicolumn{2}{|c|}{$\begin{array}{c}\text { Tacticity } \\
(\%)\end{array}$} \\
\hline & & & & & I $\mathrm{H}$ & $\mathbf{S}$ \\
\hline 20 & AIBN $^{b}$ & 0.05 & 30 & 86 & 236 & 62 \\
\hline 26 & AIBN & 0.05 & 60 & 89 & 241 & 57 \\
\hline 38 & $\mathrm{Et}_{2} \mathrm{AlNPh}_{2}{ }^{\mathrm{c}}$ & 0.25 & -40 & 94 & 827 & 65 \\
\hline 47 & $\mathrm{PhMgBr}$ & 0.28 & 20 & 68 & 2836 & 36 \\
\hline
\end{tabular}

a Monomer $5 \mathrm{mmol}$, Toluene $10 \mathrm{ml}$, Time $24 \mathrm{hr}$

b Time 42 hr, c Time $92 \mathrm{hr}$.

the polymer was composed of three tactic configurations in nearly equal amounts.

Polymerization of Benzyl Methacrylate

The results of the polymerizations of benzyl methacrylate carried out in toluene by $n$-BuLi are given in Table VI. The yield of the polymer decreased by increasing the temperature.

Table VI. Polymerization of BMA in toluene by $n$-BuLi ${ }^{\mathrm{a}}$

\begin{tabular}{rrrrrr}
\hline No. & \multirow{2}{*}{$\begin{array}{c}\text { Temp. } \\
\left({ }^{\circ} \mathrm{C}\right)\end{array}$} & $\begin{array}{l}\text { Yield } \\
(\%)\end{array}$ & \multicolumn{3}{c}{ Tacticity $(\%)$} \\
\cline { 4 - 6 } & & & I & H & S \\
\hline 50 & -78 & 99 & 81 & 15 & 4 \\
51 & -30 & 91 & 76 & 18 & 6 \\
52 & 0 & 72 & 73 & 22 & 5 \\
53 & 30 & 62 & 73 & 22 & 5 \\
54 & 60 & 16 & 61 & 32 & 7 \\
\hline
\end{tabular}

a Monomer $10 \mathrm{mmol}$, Toluene $10 \mathrm{~m} l, n$-BuLi 0.5 mmol, Time $24 \mathrm{hr}$.

The NMR spectra of the polymer prepared in toluene at various temperatures were taken in nitrobenzene- $d_{5}$ (Figure 2). In the $\alpha$-methyl region there are three peaks at $1.13,0.93$ and $0.75 \mathrm{ppm}$ corresponding to isotactic, heterotactic and syndiotactic triads. ${ }^{20}$ The polymer obtained at $-78^{\circ} \mathrm{C}$ had a predominantly isotactic structure although the isotacticity was lower than that of the PDMA obtained under the same conditions. By increasing the polymerization temperature the fraction of isotactic triads in the polymer gradually decreased and the fraction of heterotactic triads increased, while that of syndiotactic triads remained almost constant.

In the spectrum of isotactic polymers obtained at $-78^{\circ} \mathrm{C}$ the resonances of methylene protons in the polymer chain show an $\mathrm{AB}$ quartet. As the

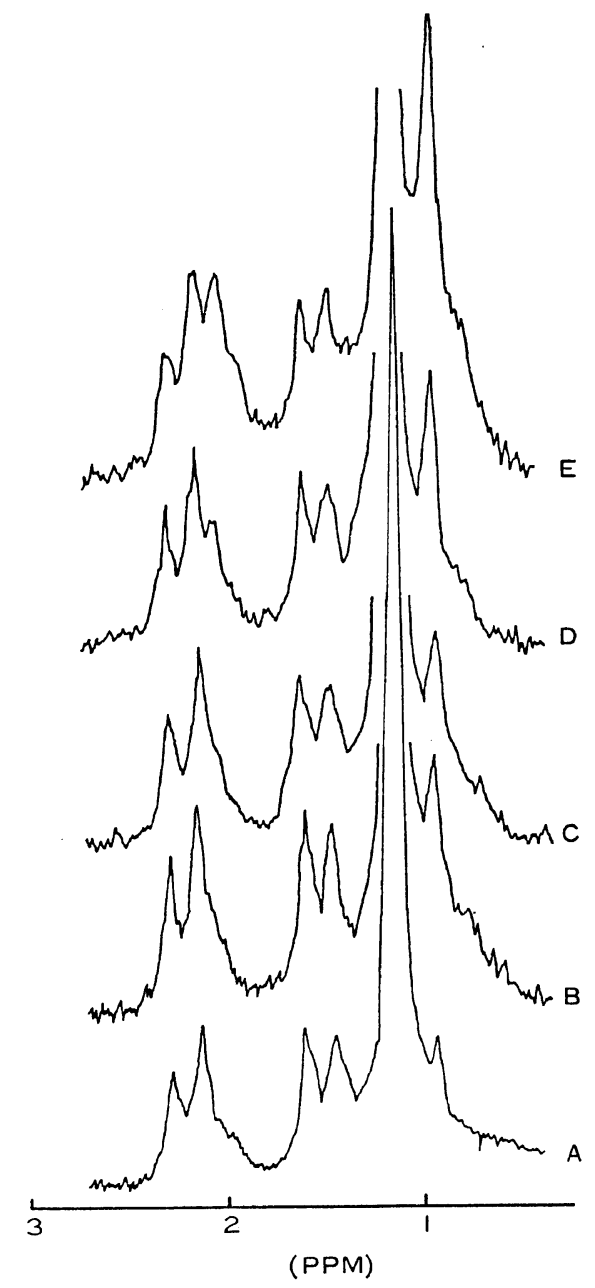

Figure 2. NMR spectra of PBMAs prepared in toluene by $n-\mathrm{BuLi}$ at various temperatures: (A) -78 , (B) -30 , (C) 0 , (D) 30 , and (E) $60^{\circ} \mathrm{C}$.

isotacticity decreased by increasing the polymerization temperature, a new peak appeared at $2.00 \mathrm{ppm}$ and the intensity gradually increased. The tactic dyads calculated from the fractions of triads were compared with those determined from the intensities of the signals in the methylene region assuming that the new peak was attributable to the racemic protons. The result (Table VII) showed the validity of this assumption. Considering the results of the tacticity analysis for tetrads in $\mathrm{PMMA}^{21,22}$ we can assign this signal to $\mathrm{mrm}$ tetrad of monomer units, where $m$ and $r$ represent meso and racemic dyads, respectively. 
Table VII. The fraction of tactic diads in PBMA prepared in toluene by $n-\mathrm{BuLi}$

\begin{tabular}{lccccccc}
\hline & Polymer & & \multicolumn{2}{c}{ Found $^{\mathrm{a}}(\%)$} & & \multicolumn{2}{c}{ Calcd. ${ }^{\mathrm{b}}(\%)$} \\
\cline { 1 - 2 } \cline { 7 - 8 } \cline { 7 - 8 } No. & $\begin{array}{c}\text { Polymn. } \\
\text { temp. }\left({ }^{\circ} \mathbf{C}\right)\end{array}$ & & meso & racemic & & meso & racemic \\
\hline 50 & -78 & & 89 & 11 & & 88 & 12 \\
51 & -30 & & 86 & 14 & & 85 & 15 \\
52 & 0 & & 85 & 15 & & 84 & 16 \\
53 & 30 & & 85 & 15 & & 84 & 16 \\
54 & 60 & & 79 & 21 & & 77 & 23 \\
\hline
\end{tabular}

${ }^{a}$ Determined from the intensities of the signals in the methylene region assuming that the peak at $2.00 \mathrm{ppm}$ is due to the racemic protons.

${ }^{b}$ Calculated from the fractions of tactic triads.

Table VIII. Polymerization of BMA in THF by $n-\mathrm{BuLi}^{\mathrm{a}}$

\begin{tabular}{|c|c|c|c|c|c|c|}
\hline \multirow{2}{*}{ No. } & \multirow{2}{*}{$\begin{array}{c}\text { Temp. } \\
\left({ }^{\circ} \mathrm{C}\right)\end{array}$} & \multirow{2}{*}{$\begin{array}{l}\text { Yield } \\
(\%)\end{array}$} & \multicolumn{3}{|c|}{ Tacticity $(\%)$} & \multirow{2}{*}{$4 \mathrm{IS} / \mathrm{H}_{2}$} \\
\hline & & & I & $\mathbf{H}$ & $S$ & \\
\hline 56 & & 7 & 6 & 31 & 63 & 1.51 \\
\hline 57 & 0 & 31 & 18 & 33 & 49 & 3.12 \\
\hline
\end{tabular}

${ }^{a}$ Monomer $10 \mathrm{mmol}$, THF $10 \mathrm{ml}, n$-BuLi $0.5 \mathrm{mmol}$, Time $24 \mathrm{hr}$.

The results given in Figure 2 show that the fraction of $\mathrm{mrm}$ tetrads in the polymer prepared in toluene increased as the polymerization temperature increased. In the spectrum of the polymer obtained in THF at $-78^{\circ} \mathrm{C}$ the racemic methylene signals are centered at $1.78 \mathrm{ppm}$ with a shoulder at $1.88 \mathrm{ppm}$. These observations may indicate that the racemic methylene resonance splits into three components at 1.78, 1.88 and 2.00 corresponding to $\mathrm{rrr}, \mathrm{mrr}$ and $\mathrm{mrm}$ tetrads.

The results of the polymerization in THF by $n$-BuLi are given in Table VIII. As the polymerization temperature increased, the yield of the polymer decreased.

When the polymerization was carried out at $-78^{\circ} \mathrm{C}$, an atactic polymer rich in syndiotactic configuration was obtained. With the elevation of the polymerization temperature, the fraction of syndiotactic triads in the polymer decreased and that of isotactic triads increased, the fraction of heterotactic triads remaining almost constant.

\section{NMR Spectra of Isotactic and Syndiotactic PDMAs at Various Temperatures}

The NMR spectra of isotactic PDMA were measured in nitrobenzene- $d_{5}$ at various tempera-

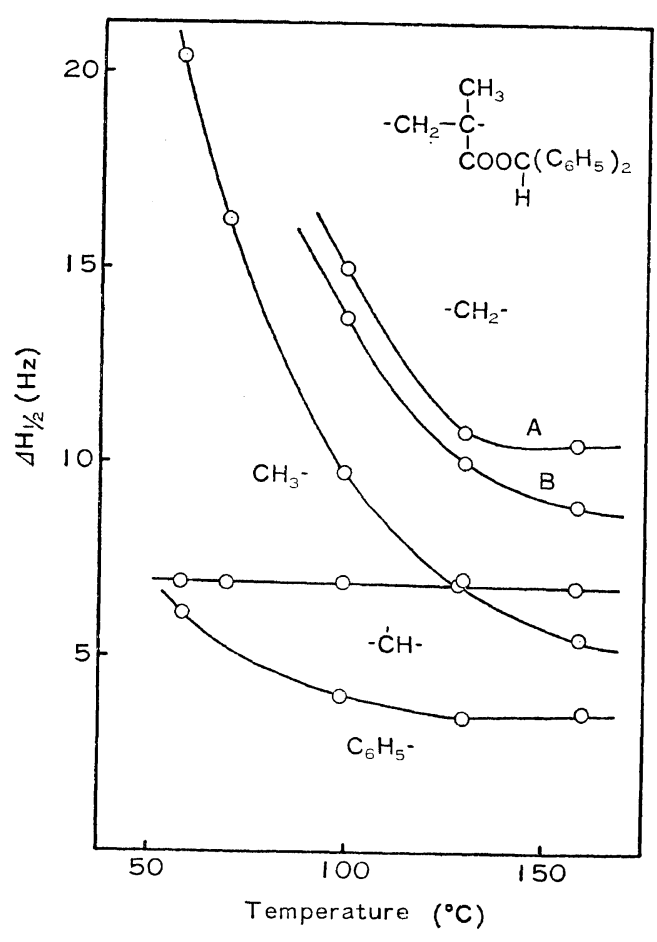

Figure 3. Temperature dependence of the half height width, $\Delta H_{1 / 2}$, of the signals in the NMR spectra of isotactic PDMA in nitrobenzene $d_{5}$.

The line width of methylene signals is represented by those of two inner peaks among the quartet. A and $\mathrm{B}$ designate the $\Delta H_{1 / 2}$ of the peaks at 2.25 and $1.90 \mathrm{ppm}$, respectively.

tures. At room temperature the spectrum showed very broad and unresolved signals, especially in $\alpha$-methyl and methylene resonances. By increasing the temperature of measurement the resonance lines became narrower and a better resolution was attained. The temperature dependence of the half height width of the signals, $\Delta H_{1 / 2}$, in the spectra of isotactic PDMA is shown in Figure 3. While carrying out the measurements, the regular checks of line width were done for the singlet peak at about $8.0 \mathrm{ppm}$ due to the $o$-proton of nitrobenzene to ensure the magnetic field in the spectrometer being uniform. The line width of the phenyl protons was respresented by the three fourths height width of the peak at about $7.40 \mathrm{ppm}$ among the fine splittings (Figure 1).

By increasing the temperature, remarkable narrowings were observed in the $\alpha$-methyl and 
methylene resonances. The decrease in line width becomes slower above $120-130^{\circ} \mathrm{C}$. The line width of the signals of phenyl and methine protons in the ester group is small even at $50^{\circ} \mathrm{C}$ and almost independent of the temperature, although it was slightly decreased by increasing the temperature.

The line width of $\alpha$-methyl and of methylene resonances is related to the segmental motions of the main chain and those of phenyl and methine resonances to the motions of side chain. ${ }^{23}$ The narrower the peak, the more rapid the motions of the chain segments. The results obtained here suggest that the main chain segments of isotactic PDMA dissolved in nitrobenzene have a rather rigid conformation up to a fairly higher temperature than in the case of $\mathrm{PMMA}^{23}$ and of poly (styrene). ${ }^{24}$ The conformation is probably close to a helical one as in the solid state.

Similar experiments were carried out on a syndiotactic PDMA. The result is shown in Figure 4. In this case the line width of phenyl proton res-

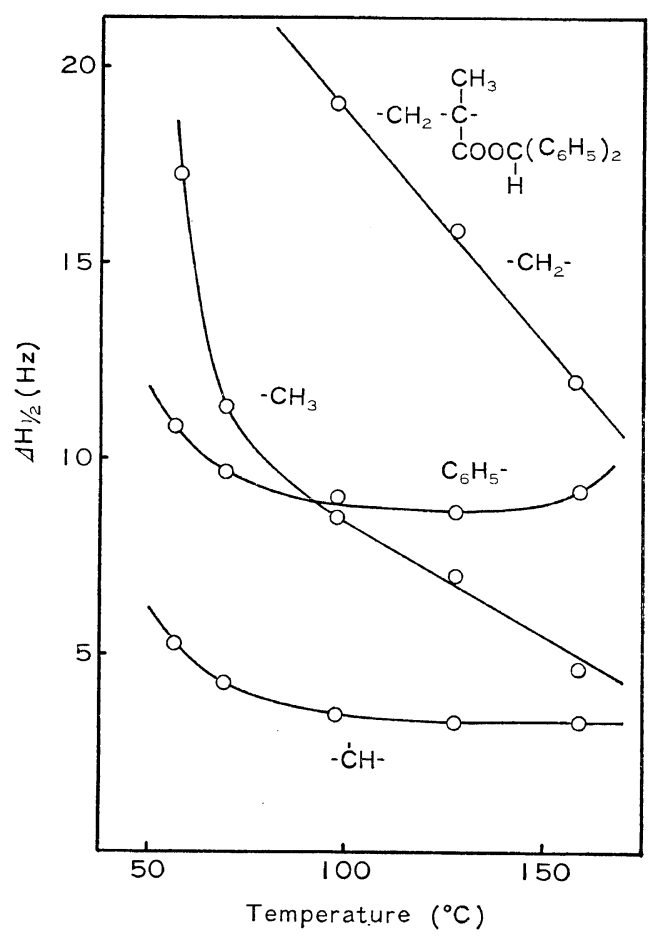

Figure 4. Temperature dependence of the half height width, $\Delta H_{1 / 2}$, of the signals in the NMR spectra of syndiotactic PDMA in nitrobenzene- $d_{5}$. onance is represented by the half height width of the poorly resolved multiplet (Figure 1). Remarkable narrowings also occurred in the $\alpha$ methyl and methylene resonances with increasing temperature. The temperature, where the decrease in their line width becomes slower, is probably above $150^{\circ} \mathrm{C}$. The line width of phenyl and methine signals was almost temperature-independent as in the case of an isotactic polymer.

\section{DISCUSSION}

A polymer having about $75 \%$ isotacticity in triad was obtained regardless of the polymerization temperature in the polymerization of MMA by $n-\mathrm{BuLi}$ in nonpolar medium. ${ }^{25}$ In this polymerization it is postulated ${ }^{26-29}$ that the lithium atom can coordinate with the carbonyl oxygen of the penultimate monomer unit in the growing chain and the resulting cyclic intermediate dominates the conformation of the incoming monomer toward the lithium atom to give an isotactic polymer. The important factors for controlling the addition mode of the incoming monomer are the formation of the O-Li coordinate linkage and the steric interactions between substituent groups of the growing chain and of the incoming monomer.

It is also suggested ${ }^{30}$ from the examination of molecular models that isotactic placements are sterically almost impossible unless the polymer chain is in helical conformation and the reacting monomer approaches from the direction corresponding to a continuation of the helix. On the other hand syndiotactic placements appear equally probable with a wide variety of conformations of the existing chain and with a wide variety of directions of approach of the reacting monomer, although they always require a certain distortion of bond lengths and angles. In a polar solvent the propagating polymer end is considered to be a free anion and generally the requirements for a stereospecific propagation should be similar to those in free radical polymerization, in which a syndiotactic placement is favored at low temperature.

The polymerization of TMA by $n$-BuLi gave a highly isotactic polymer in a nonpolar solvent as well as in a polar solvent such as THF. Moreover the polymer obtained in radical polymeriza- 
tion by the AIBN catalyst had about $60 \%$ isotacticity in triads. These results indicate that the mechanism of stereoregulation in this polymerization is different from that in the polymerization of MMA. In TMA polymerization the stereoregulation may be attributed to the growing chain itself, where syndiotactic placements are unfavorable not only in anionic but also in radical polymerization because of the bulkiness of trityl group.

In the polymerization of methacrylate having a bulky ester group, such as $t$-butyl group, by $\mathrm{LiAlH}_{4}-\mathrm{THF}$ initiator it is postulated that the bulky ester group in the penultimate unit of the growing chain prevents the succession of syndiotactic dyads. ${ }^{10}$ In the polymerization of TMA the bulkiness of trityl group prevents the syndiotactic placement and makes the helical conformation of the isotactic chain more rigid. This may force the addition mode of the monomer to be more and more favorable for an isotactic propagation resulting in the production of a highly isotactic polymer. The interaction between the lithium atom and the carbonyl oxygen is considered to be less important for the stereoregulation in the anionic polymerization of this monomer. The concept of this growing-chain-controlled mechanism of stereoregulation seems to be similar to the hypothesis of helical growth in the polymerization of $\alpha$-amino- $\mathrm{N}$-carboxylic acid anhydride. ${ }^{31-33}$

In the polymerization of DMA by $n$-BuLi a highly isotactic polymer was obtained in toluene at lower temperatures and a syndiotactic one in THF. The radical polymerization gave a predominantly syndiotactic polymer. However, the temperature dependence of the NMR signalwidth of the isotactic polymer (Figure 3 ) indicates that the conformational arrangement of the polymer chain in solution is very rigid up to a fairly high temperature. From these results it is expected that the growing-chain-controlled mechanism may contribute to some extent to the stereoregulation in the polymerization of this monomer in toluene, although it is less important than in the polymerization of TMA. The stability of the conformation, probably a helical one, increases with decreasing temperature. So the higher isotacticity of the polymer obtained in toluene at lower temperatures may be attributed somewhat to this stereoregulation mechanism.

In the syndiotactic polymerization of DMA in THF the value $4 \mathrm{IS} / \mathrm{H}^{2}$ greatly deviates from unity especially at the polymerization temperature below $0^{\circ} \mathrm{C}$ (Table IV). This indicates that the stereoregulation in this polymerization cannot obey a single parameter process ${ }^{19}$ as described for the polymerization of MMA in THF. The bulky ester group of DMA may affect the stereoregulation, but in a different manner from the polymerization of TMA.

In the polymerization of BMA in toluene by $n$-BuLi the isotacticity of the polymer is similar to that of PMMA $^{25}$ obtained under the same conditions, although it gradually decreased by increasing the polymerization temperature. This indicates that the main controlling factor of the stereoregulation is the interaction between the lithium atom and the carbonyl oxygen as in the polymerization of methyl methacrylate.

It must be noted that the fraction of $\mathrm{mrm}$ (or $d d l l$ ) tetrads in the polymer increases by increasing the polymerization temperature as an indication of minor stereoregulation in the growing chain itself.

In the polymerization of BMA by $n-\mathrm{BuLi}$ in THF the yield of the polymer was greatly depressed with increasing the polymerization temperature as in the polymerization of MMA in $\mathrm{THF}^{25}$. The temperature dependence of the tacticity in PBMA is also similar to that in PMMA but different from that in PDMA as shown in Figure 5. Thus, BMA behaves very similarly to MMA in the polymerization by $n$-BuLi in THF. Probably the same polymerization mechanisms can be applied to both monomers.

However, the $4 \mathrm{IS} / \mathrm{H}^{2}$ value deviates from unity, especially at higher polymerization temperature. It is reported that lithium methoxide is produced during the butyllithium-initiated polymerization of methyl methacrylate as a result of a termination reaction ${ }^{34,35}$, the occurrence of which is enhanced by increasing the polymerization temperature. ${ }^{36}$ The alkoxide may complex with the growing chain end and may affect the stereospecificity. Some effect of the lithium benzoxide may be considered as a factor on the stereoregulation of this polymerization. 


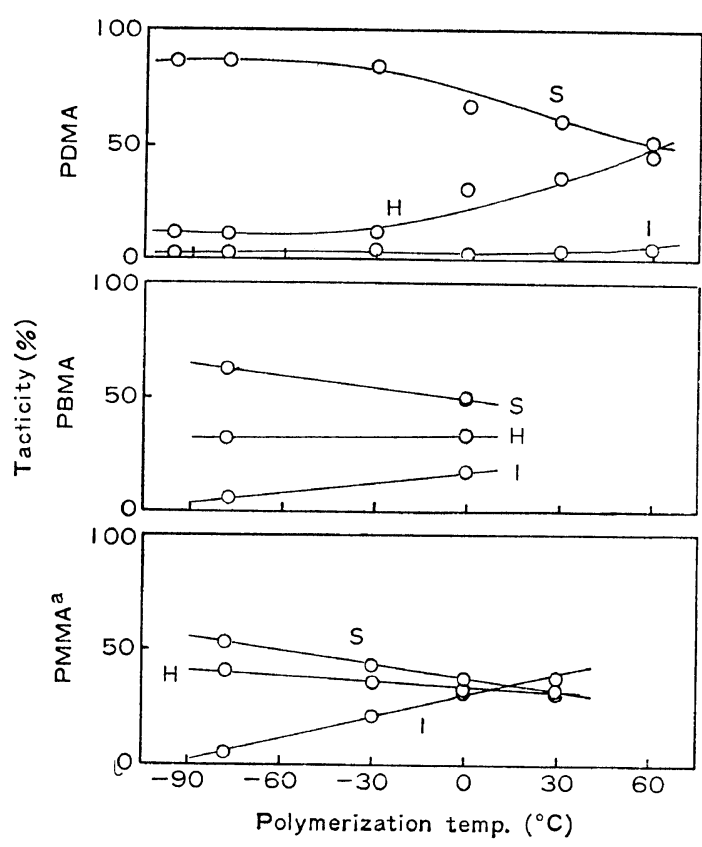

Figure 5. Tacticity of poly (methacrylates) prepared at various temperatures in THF by $n$-BuLi.

a Data from the reference 25 .

$\mathrm{PhMgBr}$, which gave a highly isotactic PMMA in toluene, ${ }^{37}$ polymerizes DMA to an atactic polymer and cannot polymerize TMA. $\mathrm{Et}_{2}-$ $\mathrm{AlNPh}_{2}$ gave a syndiotactic polymer in the polymerization of MMA in toluene. ${ }^{38,39}$ DMA was also polymerized to a syndiotactic polymer in toluene by this catalyst, although the syndiotacticity is rather lower than that of the PMMA. TMA gave no polymer by this catalyst.

The stereospecific polymerization by these catalysts is considered to proceed by a coordinated anionic mechanism. ${ }^{10,38-40}$ In these catalyst systems the stereoregulation of polymerization seems to be more strongly affected by the steric factor of the ester group in the methacrylate, as the structure of the growing chain end is more rigid and complicated than that in the polymerization by $n$-BuLi. The bulky ester groups of DMA and TMA make the coordination of these monomers with the catalyst difficult. The stereoregularities and the reactivities of these monomers are lowered by this reason.

Aknowledgement. The authors are much indebted to Mr. Y. Terawaki and Mr. H. Okuda for the measurements of NMR spectra and to Mrs. F. Yano and Mr. K. Nagata for clerical assistance in preparing the manuscript.

\section{REFERENCES}

1. T. G. Fox, B. S. Garrett, W. E. Goode, S. Gratch, J. F. Kincaid, A. Spell, and J.D. Stroupe, $J$. Amer, Chem. Soc., 80, 1768 (1958).

2. T. G. Fox and H. W. Schnecko, Polymer, 3, 575 (1962).

3. D. L. Glusker and R. A. Evans, J. Amer. Chem. Soc., 86, 187 (1964).

4. H. Sobue, K. Matsuzaki, and S. Nakano, $J$. Polym. Sci., Part A, 2, 3339 (1964).

5. K. Matsuzaki, H. Kubota, A. Ishida, K. Eto, K. Itagaki, and H. Sobue, Kogyo Kagaku Zasshi, 65, 600 (1962).

6. K. Matsuzaki, T. Okamoto, A. Ishida, and H. Sobue, J. Polym. Sci., Part A, 2, 1105 (1964).

7. G. Natta, P. Longi, and E. Pellino, Makromol. Chem., 71, 212 (1964).

8. H. Kanai, T. Makimoto, and T. Tsuruta, Kogyo Kagaku Zasshi, 68, 1947 (1965).

9. K. Matsuzaki, A. Ishida, and N. Tateno, $J$. Polym. Sci., Part C, No. 16, 2111 (1967).

10. T. Tsuruta, T. Makimoto, and H. Kanai, $J$. Macromol. Chem., 1, 31 (1966).

11. H. Yuki, K. Hatada, Y. Kikuchi, and T. Niinomi, J. Polym. Sci., Part B, 6, 753 (1968).

12. N. A. Adrova and L. K. Prokhorova, Vysokomol. Soedin., 3, 1509 (1961).

13. J. Marshall, J. Chem. Soc., 107, 515 (1915).

14. T. White, J. Chem. Soc., 1943, 238.

15. A. Weissberger and E. S. Proskauer, "Organic Solvents," 2nd. Ed., Interscience Publishers, Inc., New York (1955).

16. K. Ziegler and H. G. Gellert, Ann., 567, 179 (1950).

17. S. Murahashi, T. Niki, T. Obokata, H. Yuki, and K. Hatada, Kobunshi Kagaku, 24, 198 (1967).

18. A. Katchalsky and H. Eisenberg, J. Polym. Sci., 6, 145 (1951).

19. F. A. Bovey and G. V. D. Tiers, J. Polym. Sci., 44, 173 (1960).

20. Y. Ishii: J. Polym. Sci., Part B, 3, 771 (1965).

21. H. I. Frish, C. L. Mallows, and F. A. Bovey, J. Chem. Phys., 45, 1565 (1966).

22. K. Hatada, K. Ota, and H. Yuki, J. Polym. Sci., Part B, 5, 225 (1967).

23. Y. Kato and A. Nishioka, J. Polym. Sci., Part B, 3, 739 (1965). 
24. K. J. Liu and R. Ullman, Polymer, 6, 100 (1965).

25. H. Yuki, K. Hatada, and T. Niinomi, unpublished data.

26. C. E. H. Bawn, Proc. Chem. Soc., 1962, 165.

27. C. E. H. Bawn and A. Ledwith, Quart. Rev. (London), 16, 361 (1962).

28. D. J. Cram and K. R. Kopecky, J. Amer. Chem. Soc., 81, 2748 (1959).

29. D. J. Cram, J. Chem. Educ., 37, 317 (1960).

30. T. G. Fox, W. E. Goode, S. Gratch, C. M. Huggett, J. F. Kincaid, A. Spell, and J. D. Stroupe J. Polym. Sci., 31, 173 (1958).

31. R. D. Lundberg and P. Doty, J. Amer. Chem. Soc., 79, 3961 (1957).

32. R. E. Nylund and W. G. Miller, Biopolymers, 2, 131 (1964).
33. K. Matsuura, S. Inoue, and T. Tsuruta, Makromol. Chem., 85, 284 (1965).

34. W. E. Goode, F. H. Owens, and W. L. Myers, J. Polym. Sci., 47, 75 (1960).

35. P. Rempp, V. I. Volkov, J. Parrod, and Ch. Sadron, Bull. Soc. Chim. France, 1960, 919.

36. D. M. Wiles and S. Bywater, J. Phys. Chem., 68, 1983 (1964).

37. A. Nishioka, H. Watanabe, K. Abe, and Y. Sono, J. Polym. Sci., 48, 241 (1960).

38. S. Murahashi, T. Niki, T. Obokata, H. Yuki, and K. Hatada, Kobunshi Kagaku, 24, 198 (1967).

39. S. Murahashi, T. Obokata, H. Yuki, and K. Hatada, Kobunshi Kagaku, 24, 309 (1967).

40. J. Furukawa, Polymer, 3, 487 (1962). 